\title{
Secondary analysis of snake bite data in the Western Region of Ghana: 2006- 2010
}

\author{
Ebenezer K. Mensah ${ }^{1}$, Kwaku Karikari ${ }^{2}$, Moses Aikins ${ }^{3}$, Linda Vanotoo, Samuel Sackey ${ }^{3}$, Chima \\ Ohuabunwo ${ }^{3}$, Fred Wurapa ${ }^{3}$, Tweneboah K. Sifah ${ }^{2}$ and Edwin Afari ${ }^{3}$
}

Ghana Med J 2016; 50(2): 103-106 DOI: http://dx.doi.org/10.4314/gmj.v50i2.8

${ }^{1}$ Public Health Laboratory, P.O. Box 229 Sekondi, Ghana ${ }^{2}$ Western Regional Health Directorate, Ghana Health Service, Sekondi, Ghana ${ }^{3}$ School of Public Health, University of Ghana, Legon, Ghana

Corresponding author: Emmanuel K. Mensah

E-mail: otuamic@yahoo.co.uk

Conflict of interest: None declared

\section{SUMMARY}

Background: A snake bite is an injury caused by a bite from a snake, often resulting in puncture wounds, amputations and sometimes envenomation. Envenoming resulting from snake bite is a particularly important public health problem in rural areas of tropical and sub-tropical countries in Africa. This paper reports the incidence of snake bites and its associated mortality in the Western Region of Ghana.

Method: The study was a descriptive cross-sectional review of 2006 - 2010 snake bite secondary data generated by the Western Regional Health Information Office in Ghana. Data was extracted from the District Health Information Management System (DHIMS) database. Data was managed and analyzed using SPSS Version 16.0. Univariate analyses were expressed as percentages and graphs.

Results: The year 2009 recorded the highest incidence of Snake bites in the Western Region with Juabeso district recording the highest incidence of snake bites over the study period. Over the period about $55 \%$ of the incidence was between $50-100$ per 100,000 population. The total number of snake bites recorded in the region for the period was 7,275 , of which $52 \%(3,776)$ were males. About $60 \%$ of the patients were of the age group 15-49 years. A total of 12 reported snake bite deaths were recorded, of which $67 \%$ were men. This study recommends to the Districts Health Directorates in the Western Region to regularly organize community education on snake bite and the use of protective clothing by the farmers.

Funding: None declared

Keywords: Snake bite, Envenomation, Incidence, District Health Information Management System, Western Region, Ghana

\section{INTRODUCTION}

A snake bite is an injury caused by a bite from a snake, often resulting in puncture wounds inflicted by the animal's fangs and sometimes resulting in envenomation. It is a life-threatening medical emergency when envenomation occurs. Envenoming resulting from snake bite is a particularly important public health problem in rural areas of tropical and sub-tropical countries in Africa. In these areas snake bite affects poorer rural populations; mainly those involved in subsistence farming activities. Poor access to health services in these settings and, in some instances, a scarcity of anti-venom often leads to poor outcomes and considerable morbidity and mortality. Many snake bite victims fail to reach hospitals in time or seek medical care after a considerable delay because they first seek treatment from traditional healers.

Some even die before reaching the hospital. Hospital statistics on snake bites therefore underestimate the true burden.

Globally, around 5.5 million people are bitten by snakes each year, resulting in some 400,000 amputations and between 20,000 and 125,000 deaths. ${ }^{1}$ It has been estimated that one million snake bites occur every year in Africa, primarily in Sub-Saharan Africa, resulting in 100,000 to 500,000 envenomations and 10,000 to 30,000 deaths. $^{2}$ The forests in the Western region are abundant with venomous snakes such as black cobras, green mambas and gaboon vipers. Non-venomous snakes found in the forest zones include Boas and pythons. 
The rain forest serves as a perfect environment for these snakes, being that snakes are cold blooded and the rain forest is moist and warm.

In 2009, snake bite was declared by World Health Organization (WHO) as a neglected tropical disease. ${ }^{1}$ Snake bite is one of the disease conditions that are reported under monthly out-patients morbidity returns in the Western Region, and there is no reported epidemiological data analysis on the situation. There is therefore the need to review the data on snake bites to show district incidence, distribution by age and sex and the mortality in the Western Region of Ghana.

\section{METHODS}

Study area: The study was conducted in the Western Region which is situated in the South-Western part of Ghana. It is bordered on the east by the Central Region, to the west by the Côte d'Ivoire, to the north by Ashanti and Brong Ahafo Regions, and to the south by the Gulf of Guinea. The Western Region had a population of 2,376,021 according to 2010 Population Census. It has $75 \%$ of its vegetation within the high forest zone of Ghana; and the wettest part of Ghana with an average rainfall of $1,600 \mathrm{~mm}$ per annum. Agriculture excluding fishing remains the biggest industrial activity in the Western Region employing more than $50 \%$ of workers. The forest zones in the Western Region have abundant flora predominately Makore, Dahoma, Kyaya and Bamboos. The region's forest zones are also occupied by many fauna such as birds, monkeys, butterflies and African elephants.

Study design: The study was a descriptive crosssectional review of 2006 - 2010 snake bite secondary data generated by the Western Regional Health Information Office in Ghana.

Study population and sample: The study population was all reported snake bite patients in public health facilities in the Western Region of Ghana.

Data collection techniques: Secondary data generated by Western Regional Health Information Department over a five year period, 2006-2010 was used. Data was extracted from the District Health Information Management System (DHIMS) database. The DHIMS is a comprehensive software for reporting and analyzing collected routine health service data on health services, morbidity, mortality and diseases. Information from the DHIMS is used by health managers for planning, budgeting and decision making.

Data analysis: The background characteristics of age group and sex distribution of the snake bite patients were obtained by cross tabulation using SPSS Version 16.0. Univariate analyses were expressed as percentages and graphs.

Ethical clearance: No formal approval was sought from any institutional review body in the country. However, approval was sought from the Western Regional Health Administration and the Western Regional Health Information Department for the study. Snake bite data was securely kept, treated confidential and used purposely according to the objective of the study.

\section{RESULTS}

\section{Incidence of snake bite}

Figure 1 shows the incidence of snake bites over the study period..

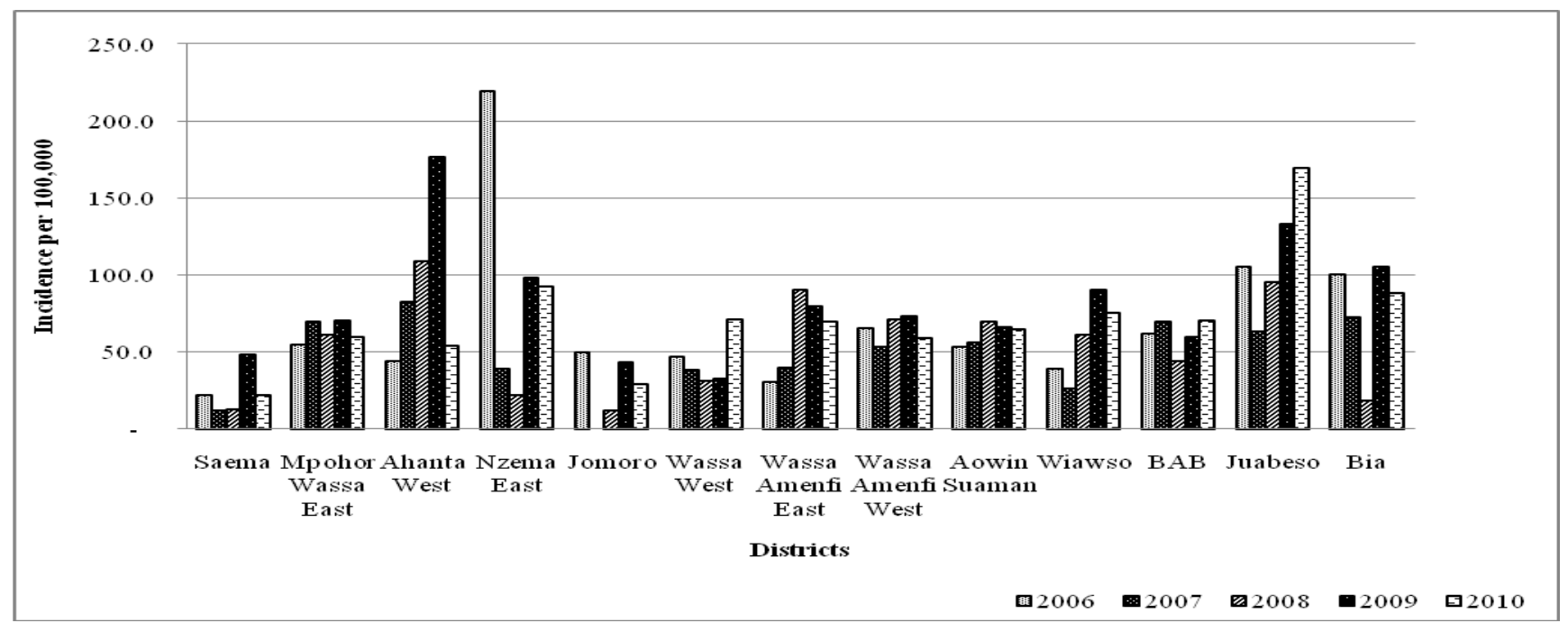

Figure 1 Annual incidence of snake bite cases by districts in the Western Region, 2006-2010 
The annual overall average shows that the year 2009 recorded the highest incidence $(82.8$ per 100,000$)$ and 2007 recorded the lowest average of 47.9 per 100,000 .

The district overall average also indicates that Juabeso district recorded the highest incidence (113.4 per 100,000) and Saema district the lowest of 23.3 per 100,000. However, Nzema East district recorded high incidence in 2006, Ahanta West district in 2009 and Juabeso district in 2010 .

Furthermore, $34 \%$ of all the incidence was less than 50 per 100,000 , about $54 \%$ was between $50-100$ per
100,000 and remaining $12 \%$ was above 100 per 100,000 .

\section{Age and sex distribution of snake bite}

The total number of snake bites recorded in the region for the period was 7,275 , of which $52 \%(3,776)$ were male patients. About $60 \%$ of the patients were of the age group 15-49 years, with the highest percentage of snake bites occurring in the age group 20-34 years whilst the least occurrence was in children less than 1year as shown in Figure 2. Generally, there was an even distribution of snake bites among males and females across all the age groups.

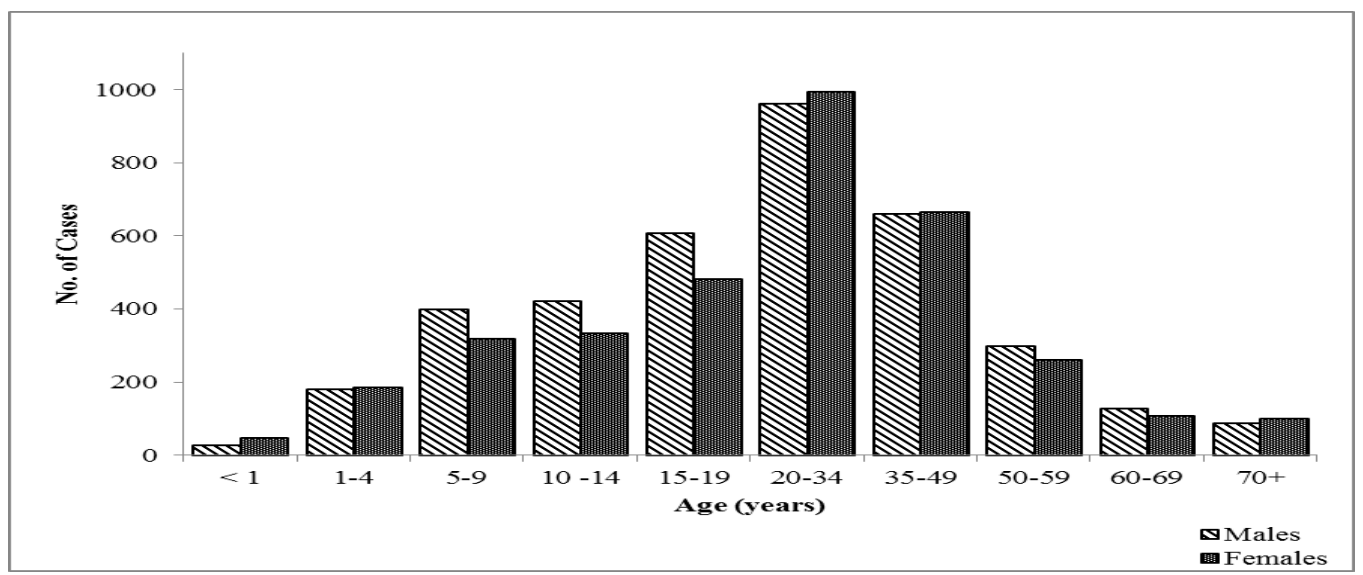

Figure 2 Age and sex distribution of cumulative snake bite in the Western Region, 2006-2010

\section{Mortality associated with snake bite}

There were 1,091 snake bite admissions in health facilities with $7(0.6 \%)$ deaths. The 7 deaths on admission were part of a total of 12 reported snake bite deaths from 2006-2010, of which $67 \%$ were men. Male deaths predominate in all age groups. Highest deaths occurred within the age group 31 years and over, of which $57 \%$ were men, and the under 1 year death was a male (Figure 3).

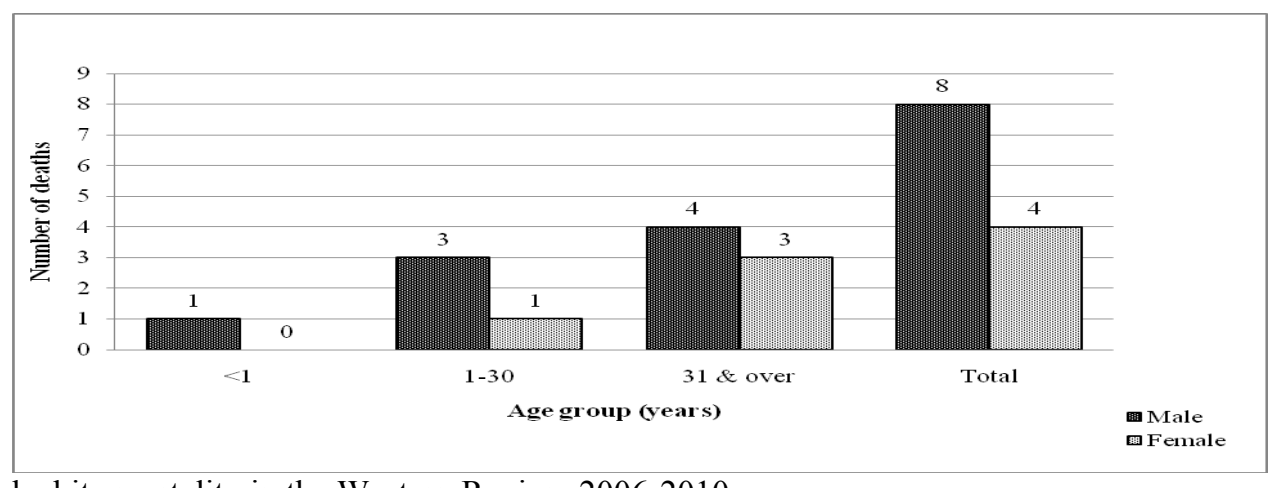

Figure 3 Snake bite mortality in the Western Region, 2006-2010.

\section{DISCUSSION}

This data review shows that Snake bite is common in the Western Region as in other regions throughout the world. In this study frequent number of cases reported during the period under review is similar with previous studies done on snake bites in India and Pakistan., 4 The risk of snake bite is high in the region. This could be due to their main economic activity (i.e., farming) and the nature and type of fauna in the region which 
grows well due to the favourable climate (i.e., low temperature and heavy rainfall).

The low case fatality rate recorded despite high cases of snake bite could be attributable to bites by nonvenomous snakes or availability of anti-snake venom at the health facilities, since the Western Regional Health Directorate had distributed 3,673 anti-snake venom doses to all districts to combat snake bites cases.

Juabeso district recorded the highest number of snake bites. This district is located in the northern part of the region with a high tropical forest. These high cases could be due to the presence of abundant vegetation which is rich in flora and fauna, farming activities and scattered population in the forest using forest paths, thus making the people in this area particularly prone to snake bites. The snake bites incidence peaks in Nzema East district (2006), Ahanta West district (2009) and Juabeso (2010) could be due to the victims reporting cases to the health facilities as a results of an awareness created to report all cases by the district health administrations.

This study found both males and females being at risk of snake bites. In India, a similar study found females being bitten more than males ${ }^{5}$. Other studies also reported males being affected 2-3 times more commonly than females. ${ }^{6,7}$

While snake bites were observed in all age groups, those at high risk were aged 15-49 years. People in this age group form the most active economic age group. They are often found in the open and are involved in active farming and hence at the highest risk of snake bites. Of much concern are the frequent cases of snake bites among children less than 15 years and especially those under one year. This has important public health implications as these age groups should be given priority in directing any intervention for snake bites. These differences may be attributable to what the individuals may be doing at the time of snake bite. In West Africa, for example, children and farmers in rural communities are commonly identified as being the highest snake bite risk groups. ${ }^{8,9,10}$

Data on snake bites do not include information such as type of snake, site of bite, nature of activity at the time of bite, time of day, incidence of bites in relation to the time of the year and whether anti-snake venom was given. Secondly, the secondary data has limited disaggregation such as by marital status, occupation, and residency. Finally, there could have been compilation errors on the part of the data entry clerks. Knowledge of these risk factors and interventions would be useful for public health providers to plan and formulate strategies and specific preventive interventions to combat snake bite related health problems in the Western Region.

\section{CONCLUSIONS}

In conclusion, snake bite is common but of low fatality in the Western Region, and the population susceptible to snake bite are children and productive young men and women. This study recommends to the Districts Health Directorates in the Western Region to regularly organize community education on snake bite and the use of protective clothing by the farmers. Also the Western Regional Health Directorate, if feasible, should expand the DHIMS data to include risk-factors and healthcare data on snake bite. Finally, further studies need to be conducted to identify the main risk factors exposing the population to snake bite and the types of snakes involved.

\section{REFERENCES}

1. Williams D., Gutiérrez J.M., Harrison R., Warrell D. A., White J., Winkel K. D., Gopalakrishnakone P. The Global Snake Bite Initiative: an antidote for snake bite. On behalf of the Global Snake Bite Initiative Working Group and International Society on Toxinology. Viewpoint. www.thelancet.com. 2010; 375: $89-91$

2. Chippaux JP. Estimate of the burden of Snake bites in Sub-Saharan Africa; A meta-analytic approach. Toxicon. 2011; 57(4): 586-99.

3. Bawaskar HS, Bawaskar PH. Profile of Snake bites envenoming in Western Maharashtra, India. Trans $R$ Soc Trop Med Hyg. 2002; 96:79-84.

4. Khichi GQ, Mannan MA, Channar MS. Snake bite: Study of 50 cases at Bahawalpur. Pak Paed J. 2003; 27(2):78-80.

5. Bhardway A, Sokhey J. Short Reports: Snake bites in the hills of North India. The Nat Med J of India. 1998; 11(6): 264-265.

6. Hati AK, Mandal M, De MK, Mukherjee H, Hati RN. Epidemiology of Snake bites in the Disrict of Burdwan, West Bengal. J Indian Med Assoc. 1992; 90:145-7.

7. Sawai Y., Honma M. Snake bites in India. Toxicon. 1995; 13 (2):120-1

8. Swiecick A.W. Snakes and Snake bite in Western Region, Ghana. J Trop Med Hyg. 1965; 68: 300-304.

9. Chippaux JP. Epidemiology of Snake bites in Cote d'Ivoire. Bull Soc Pathol Exot. 2002; 95:167-171.

10. Njoku C.H., Tsezuo S.A., Makusidi M.A. An Audit of Snake bites injuries seen at the Usman Danfodiyo University Teaching Hospital, Sokoto, Nigeria. Niger Postgrad Med J. 2008; 15:112-115. ๑ 